\title{
Molecular and Biochemical Characterization of Carbendazim-Resistant Botryodiplodia theobromae Field Isolates
}

\author{
Ye Yang, ${ }^{\dagger}$ Geng Di Zeng, Yu Zhang, Ru Xue, and Ya Juan Hu \\ Key Lab of Green Prevention and Control of Tropical Plant Diseases and Pests, Institute of Tropical Agriculture and Forestry, \\ Hainan University, Haikou, Hainan 570228, China
}

\begin{abstract}
Stem-end rot caused by Botryodiplodia theobromae is a destructive disease of mango. B. theobromae field isolates resistant to carbendazim (MBC) were collected in Hainan Province, China. In this study, the characteristics of these field isolates with resistance to $\mathrm{MBC}$ were investigated. The resistance of $B$. theobromae isolates to $\mathrm{MBC}$ was stably inherited. Both the MBC-resistant and MBC-sensitive isolates had similar mycelial growth rates, pathogenicity, sensitivity to high glucose, glycerol content, and peroxidase activity. Compared with MBC-sensitive isolates, MBC-resistant isolates were more sensitive

membrane permeability of the sensitive isolates was markedly increased compared with that of the resistant isolates. Analysis of the $\beta$-tubulin gene sequence revealed point mutations resulting in substitutions at codon 198 from glutamic acid (GAG) to alanine (GCG) in moderately resistant isolates, and at codon 200 from phenylalanine (TTC) to tyrosine (TAC) in highly resistant isolates. These $\beta$-tubulin gene mutations were consistently associated with MBC resistance. Overall, we infer that the altered cell membrane permeability and the increase in CAT and GST activities of the resistant isolates are linked to $\mathrm{MBC}$ resistance.
\end{abstract} to low temperature and had a significant decrease in sensitivity to high $\mathrm{NaCl}$ and a significant increase in catalase (CAT) and glutathione S-transferase (GST) activities. After MBC treatment, the cell
Keywords: Botryodiplodia theobromae, carbendazim, resistance mechanism
Mango (Mangifera indica L.) is one of the five main tropical fruit species in the world. It is an economically important tropical and subtropical crop. China is one of the main mango-growing areas of the world. Hainan Province ranks first in China in both the planted area and the production of mango (Zhang 2011). Mango stem-end rot is a complex disease that can be caused by a variety of pathogens, including several species of the family Botryosphaeriaceae such as Botryodiplodia theobromae, Neofusicoccum parvum, and Botryosphaeria dothidea. These pathogens cause a watery rot that starts from the stem end of the fruit and then progresses throughout the rest of the fruit (Slippers et al. 2005). Stem-end rot caused by Botryodiplodia theobromae Pat. (Lasiodiplodia theobromae (Pat.) Griffon \& Maubl.) is an important postharvest disease of mango fruit in China and worldwide (Hu et al. 2009; Karunanayake et al. 2014; Sakalidis et al. 2011). The pathogens may become established asymptomatically in the field, with the typical symptoms of the disease occurring after harvest, which is a relatively long period (Twumasi et al. 2014). $B$. theobromae is the causal agent of numerous plant diseases in a wide variety of hosts with a worldwide distribution. It causes a rapid decay of mango and other tropical fruit such as avocado, papaya, and banana, resulting in large economic losses and limiting their export. Fungicide application is still the main method to control mango diseases. The most conventional measure to reduce the incidence of stem-end rot for more than 20 years in China was the application of benzimidazole fungicides.

Benzimidazole fungicides are a class of fungicides that includes benomyl, carbendazim (MBC), fuberidazole, and thiabendazole. All are inhibitors of tubulin biosynthesis. The Fungicide Resistance Action Committee has designated benzimidazole fungicides as being

${ }^{\dagger}$ Corresponding author: Y. Yang; yyyzi@tom.com

Funding: This study was supported by the National Natural Science Foundation of China (31560521).

The author(s) declare no conflict of interest.

Accepted for publication 8 April 2019.

(C) 2019 The American Phytopathological Society at high risk for resistance development. Among them, $\mathrm{MBC}$ is a broad-spectrum fungicide with systemic activity. MBC resistance has been reported in many fungal species in China since 1994 (Yang et al. 2008; Zhou and Wang 2001; Zhou et al. 1994). The molecular target of MBC has been determined to be $\beta$-tubulin (Davidse 1986; Deising et al. 2008). Many studies have indicated that the molecular mechanism of resistance in fungi is correlated with point mutations in the $\beta$-tubulin gene that alter amino acid sequences within the benzimidazole-binding site (Albertini et al. 1999). Furthermore, various biochemical mechanisms may regulate fungicide resistance in fungi (Sevastos et al. 2017). Our previous studies indicated that $B$. theobromae isolates had high levels of resistance to $\mathrm{MBC}$, thiophanate-methyl, and azoxystrobin, and MBC-resistant (MBC$\mathrm{R})$ isolates from Hainan Province, China, were cross-resistant to thiophanate-methyl (Hu et al. 2009; Wang et al. 2015; Zhao et al. 2017). The biochemical and molecular characteristics of resistant isolates associated with $\mathrm{MBC}$ resistance of $B$. theobromae isolates were not studied. The objectives of this study were to compare the characteristics of MBC-resistant and $\mathrm{MBC}$-sensitive isolates of $B$. theobromae and to explore the possible resistance mechanisms. The approaches were as follows: (i) monitor the resistance stability of $B$. theobromae field isolates to $\mathrm{MBC}$; (ii) determine the pathogenicity, temperature sensitivity, and osmotic pressure sensitivity of isolates; (iii) compare the cell membrane permeability of mycelia; (iv) determine the mycelium glycerol content, protein content, and enzyme activity; and (v) investigate the molecular mechanism of resistance in field isolates of $B$. theobromae.

\section{Materials and Methods}

Isolates and culture conditions. In total, 152 isolates of $B$. theobromae were collected from diseased mango in Hainan Province, China in 2014 and 2016, and all isolates were tested for sensitivity to MBC. In all, $75.7 \%$ of the B. theobromae isolates were resistant to MBC (Wang et al. 2015; Zhao et al. 2017). To study the biochemical and molecular mechanisms responsible for resistance, 12 isolates of $B$. theobromae were chosen from the 152 isolates collected.

The 12 isolates were divided into three phenotypes of MBC resistance; namely, sensitive (MBC-S), which did not grow on potato dextrose agar (PDA) amended with $\mathrm{MBC}$ at $10 \mu \mathrm{g} / \mathrm{ml}$, and moderately resistant (MBC-MR) and highly resistant (MBC-HR), which 
were able to grow on PDA medium amended with $\mathrm{MBC}$ at 100 and $1,000 \mu \mathrm{g} / \mathrm{ml}$, respectively. The MBC-S isolates were YZTN10601, JSJH10101, and HLTN83108. The MBC-MR isolates were JSTN10102, YZJH10201, CJTN30204, and CJTN30205. The MBC-HR isolates were HLJH21617, SYTN12603, YCHJ80202, HLTN22602, and HLTN10402. All isolates were incubated on PDA at $28^{\circ} \mathrm{C}$.

Determination of resistance stability. Carbendazim TC $(97.2 \%$ active ingredient; Hainan Zhengye Zhongnong High Technology Co., Ltd., Haikou, China) was dissolved in $0.1 \mathrm{M}$ hydrochloric acid to a concentration of $5 \times 10^{4} \mu \mathrm{g} / \mathrm{ml}$ and stored at $4{ }^{\circ} \mathrm{C}$ in the dark.

To determine the stability of $\mathrm{MBC}$ resistance, the field isolates with the three resistance phenotypes were subjected to 10 successive transfers on fungicide-free PDA medium. At each transfer, a 7-mm mycelial plug was cut from the edge of a 3-day-old colony and placed on a PDA plate without MBC. The cultures obtained with the 1st and 10 th transfers were tested for sensitivity to MBC. The concentrations of MBC in the PDA for sensitive isolates and resistant isolates were 5 and $500 \mu \mathrm{g} / \mathrm{ml}$, respectively. The mycelial growth inhibition rate was calculated on the basis of colony diameter in control medium (no fungicide). The change in inhibition rates was expressed as the inhibition rate obtained with the 10th transfer divided by that obtained with the 1st transfer isolates according to Cai et al. (2015). All isolates were incubated at $28^{\circ} \mathrm{C}$ for $36 \mathrm{~h}$, with three replicates. The experiment was performed twice.

Determination of pathogenicity. Fresh green unripe mango fruit (cultivar Tainong) were used to test the pathogenicity of the 12 isolates. The surface of the fruit was disinfested in $1 \% \mathrm{NaOCl}$ solution for $1 \mathrm{~min}$, washed three times with sterile distilled water, and air dried. Each fruit was wounded in three places with a sterile needle, and mycelial plugs were placed on the wounded site in the mango fruit (three plugs per fruit). The fruit were placed in plastic boxes ( 287 by 195 by $95 \mathrm{~mm}$ ). The temperature and relative humidity were maintained at $30 \pm 2{ }^{\circ} \mathrm{C}$ and 70 to $90 \%$, respectively. An agar block was placed on the puncture site in a mango as a control. After incubation for 2 days, the diameter of each disease lesion was measured and recorded. There were nine replicates in the experiment. The extent of disease was assessed using lesion diameter (Zhao et al. 2017) and fruit disease scores $1=0$ to $5,2=5$ to $10,3=10$ to $20,4=20$ to 40 , and $5=>40 \mathrm{~mm}$. The disease index was computed using the formula (Karunanayake et al. 2014) disease index $=[$ (sum of all numerical ratings $\times 100) /($ total number of observations $\times$ maximum disease score)].

Determination of temperature sensitivity. Mycelial plugs ( $7 \mathrm{~mm}$ ) of each isolate were placed in the center of PDA plates. To determine the temperature sensitivity of $B$. theobromae, the isolates with the three resistance phenotypes were inoculated on PDA plates at various temperatures $\left(10,15,20,25,30,35\right.$, or $\left.40^{\circ} \mathrm{C}\right)$ for $36 \mathrm{~h}$ in the dark; then, the size of the colonies was measured and compared. Three replicates were used for each isolate, and the experiment was performed twice.

Determination of sensitivity to osmotic stress. Sensitivity to high sugar (glucose) concentrations was determined according to Duan et al. (2014). Mycelial plugs were transferred onto PDA plates containing glucose at $5,10,20,40,80,100$, or $150 \mathrm{mg} / \mathrm{ml}$. The plates were incubated at $28^{\circ} \mathrm{C}$ for $36 \mathrm{~h}$, and the colony diameters were recorded. For sensitivity to high salt $(\mathrm{NaCl})$ concentrations, the $\mathrm{NaCl}$ content was $0,1.25,2.5,5,10,20,40$, or $80 \mathrm{mg} / \mathrm{ml}$, and the colony size was determined as previously described.

Determination of the glycerol content of mycelia. The glycerol content in the mycelia was determined using a commercial assay kit (XF1012; Sail Biotechnology Co., Ltd., Shanghai, China) according to the manufacturer's instructions. Mycelia $(0.1 \mathrm{~g})$ of each isolate were harvested and ground with liquid nitrogen in a mortar. Then, the mycelial powder was transferred to a 2-ml centrifuge tube containing $1 \mathrm{ml}$ of glycerol extraction buffer. After transfer, the tube was vortexed three times for $30 \mathrm{~s}$ each and centrifuged at 5,000 $\times$ $g$ for $5 \mathrm{~min}$. The supernatant was transferred to a new tube, and $5 \mu \mathrm{l}$ of each supernatant was mixed with $195 \mu \mathrm{l}$ of glycerol detection buffer. After the mixture was incubated at $37^{\circ} \mathrm{C}$ for $10 \mathrm{~min}$, the glycerol concentration was determined with a SpectraMax M5 microplate reader (SpectraMax 190; Molecular Device Corporation, San Jose, CA, U.S.A.) at $550 \mathrm{~nm}$, with double-distilled water $\left(\mathrm{ddH}_{2} \mathrm{O}\right)$ as a control. The glycerol content of the supernatants was calculated using a standard curve. There were three replications of each treatment, and the experiment was repeated three times.

Determination of the enzyme activity of mycelia. After incubating at $28^{\circ} \mathrm{C}$ for 3 days, the mycelia were harvested and pressed to dry using filter paper. Then, the mycelia were homogenized immediately on ice in normal saline. The homogenates were centrifuged at $2,500 \times g$ for $10 \mathrm{~min}$, and the supernatants were used for protein and enzyme analyses.

Total soluble protein levels in mycelia were estimated using a Bradford protein assay kit (Nanjing Jiancheng Bioengineering Institute, Nanjing, Jiangsu, China). Bovine serum albumin was used to prepare a standard curve.

Peroxidase (POD) activity was determined according to the instructions of a POD activity assay kit (Nanjing Jiancheng Bioengineering Institute) using hydrogen peroxide $\left(\mathrm{H}_{2} \mathrm{O}_{2}\right)$ as the substrate. The increase in absorbance at $420 \mathrm{~nm}$ was measured spectrophotometrically at room temperature. One unit of POD was defined as the amount of enzyme that hydrolyzes $1 \mu \mathrm{g}$ of substrate per minute per milligram of protein at $37^{\circ} \mathrm{C}$. The catalase (CAT) activity in mycelia was estimated by a colorimetric method with ammonium molybdate. CAT was assayed using a CAT assay kit (Nanjing Jiancheng Bioengineering Institute). CAT activity was calculated by the decrease in absorbance at $405 \mathrm{~nm}$ due to the degradation of $\mathrm{H}_{2} \mathrm{O}_{2}$. One unit of CAT was defined as the quantity of enzyme that liberates $1 \mu \mathrm{M} \mathrm{H}_{2} \mathrm{O}_{2}$ per minute per milligram of protein at $37^{\circ} \mathrm{C}$.

Glutathione S-transferase (GST) activity was assayed using 1chloro-2,4-dinitrobenzene as a substrate according to the instructions of a GST kit (Nanjing Jiancheng Bioengineering Institute). The change in absorbance at $420 \mathrm{~nm}$ was measured. GST activity was expressed as units per milligram of total protein. One unit of GST activity was defined as $1 \mathrm{mg}$ of tissue protein, with the nonenzymatic reaction deducted, that catalyzes the reaction at $37^{\circ} \mathrm{C}$ in which the concentration of glutathione decreases by $1 \mu \mathrm{M}$ per minute.

Determination of the relative electrical conductivity of mycelia. Mycelial cell membrane permeability was measured according to Duan et al. (2014), with slight modifications. Mycelial plugs were inoculated into 250 -ml flasks (5 plugs/flask) containing $100 \mathrm{ml}$ of PD liquid medium ( $20 \mathrm{~g}$ of potato and $20 \mathrm{~g}$ of glucose per liter) and cultured at $28^{\circ} \mathrm{C}$ for $48 \mathrm{~h}$. Then, the mycelia were collected and washed twice with $\mathrm{ddH}_{2} \mathrm{O}$. The culture was collected by vacuum filtration through a $0.45-\mu \mathrm{m}$ cellulose acetate filter, and $1 \mathrm{~g}$ of mycelia was suspended in $20 \mathrm{ml}$ of $\mathrm{ddH}_{2} \mathrm{O}$ containing $\mathrm{MBC}$ at 0,50 , or $500 \mu \mathrm{g} / \mathrm{ml}$. After $0,5,10,20,40,80,120$, or $180 \mathrm{~min}$ at $25^{\circ} \mathrm{C}$, the electrical conductivity was measured with an electrical conductivity meter (FE38 Plus, Shanghai, China). After $180 \mathrm{~min}$, the mycelia were boiled for $5 \mathrm{~min}$ and cooled to room temperature and the final conductivity was measured. Relative conductivity was used to compare the cell membrane permeability of mycelia. The relative conductivity of mycelia was calculated as relative conductivity $(\%)=($ conductivity $/$ final conductivity) $\times 100$.

DNA extraction, polymerase chain reaction amplification, and sequencing of the $\boldsymbol{\beta}$-tubulin gene. To extract fungal DNA, isolates were cultured on PDA at $28^{\circ} \mathrm{C}$ for 3 days. Mycelia were collected from PDA and ground in liquid nitrogen. Total genomic DNA was extracted using a universal genomic DNA extraction kit (TaKaRa Biotechnology [Dalian] Co., Ltd., Dalian, China) according to the manufacturer's instructions. Genomic DNA was extracted from mycelia via the cetyltrimethylammonium bromide procedure.

Universal primers (B1 and B3) were used to amplify a fragment of the $\beta$-tubulin gene from $B$. theobromae isolates using isolated genomic DNA as a template. The primer sequences were as follows: B1 (5'-GATCACCCACTCCCTGGGTGGTGG-3') and B3 (5'CTCCATGAAAGGAGGTCGAGGAC- $3^{\prime}$ ). The polymerase chain reaction (PCR) mixture contained $10 \mu$ l of $2 \times$ Phanta Max Master Mix (Vazyme Biotech Co., Ltd., Nanjing, China), $1 \mu$ l of template DNA, $0.5 \mu l$ of $(10 \mathrm{mM})$ each primer, and $8 \mu \mathrm{l}$ of $\mathrm{ddH}_{2} \mathrm{O}$. The PCR 
conditions were $95^{\circ} \mathrm{C}$ for $5 \mathrm{~min}$ and then 34 cycles of $95^{\circ} \mathrm{C}$ for $45 \mathrm{~s}$, $57^{\circ} \mathrm{C}$ for $45 \mathrm{~s}$, and $72^{\circ} \mathrm{C}$ for $1 \mathrm{~min}$, with a final 10 -min extension at $72^{\circ} \mathrm{C}$. The PCR amplifications were performed three times independently for each isolate. An approximately $900-b p$ single PCR fragment was amplified using this pair of primers. All PCR products were separated by electrophoresis in a $1 \%$ agarose gel in Tris-acetate buffer and purified using an UNIQ gel extraction kit (Sangon Biotech Co., Ltd., Shanghai, China). Then, the purified fragments were cloned into the pMD 18-T Simple Vector (TaKaRa Biotechnology [Dalian] Co., Ltd.) and sequenced by Sangon Biotech Co., Ltd.

The DNA sequence of the $\beta$-tubulin gene was analyzed with the program DNAMAN (version 6.0; Lynnon Biosoft, U.S.A.) and InterProScan (http://www.ebi.ac.uk/interpro/search/sequence-search) and was compared with the $\beta$-tubulin genes from other fungi. For comparison of the amino acid sequences of the $\beta$-tubulin genes from MBC-R and MBC-S isolates, the DNA sequences were translated into amino acid sequences using standard code with the computer program EMBOSS Transeq (https://www. ebi.ac.uk/emboss/transeq/).

Date analysis. All of the experiments were performed at least two times on separate occasions, and the mean values \pm standard deviations were calculated. Analysis of variance followed by means

Table 1. Resistance stability to carbendazim of the field isolates of Botryodiplodia theobromae

\begin{tabular}{llcccc}
\hline & & \multicolumn{4}{c}{$\begin{array}{c}\text { Inhibition } \\
\text { rate (\%) }\end{array}$} \\
Isolates & Phenotype $^{\mathbf{x}}$ & $\begin{array}{c}\text { MBC } \\
(\boldsymbol{\mu g} / \mathbf{m l})\end{array}$ & $\mathbf{1 s t}$ & $\mathbf{1 0 t h}$ & Change in rate $^{\mathbf{z}}$ \\
\hline JSJH10101 & MBC-S & 5 & 93.4 & 93.5 & 1.0 \\
YZTN10601 & MBC-S & 5 & 93.5 & 93.7 & 1.0 \\
HLTN83108 & MBC-S & 5 & 98.3 & 98.4 & 1.0 \\
CJTN30204 & MBC-MR & 500 & 24.3 & 29.7 & 1.2 \\
CJTN30205 & MBC-MR & 500 & 32.7 & 34.2 & 1.1 \\
YZJH10201 & MBC-MR & 500 & 17.7 & 34.3 & 1.9 \\
JSTN10102 & MBC-MR & 500 & 17.3 & 14.6 & 0.8 \\
SYTN12603 & MBC-HR & 500 & 3.0 & 6.5 & 2.1 \\
YCHJ80202 & MBC-HR & 500 & -9.9 & -5.0 & 0.5 \\
HLTN22602 & MBC-HR & 500 & 6.6 & 5.7 & 0.9 \\
HLJH21617 & MBC-HR & 500 & -1.2 & -0.8 & 0.7 \\
HLTN10402 & MBC-HR & 500 & 2.89 & 1.94 & 0.7 \\
\hline
\end{tabular}

${ }^{x}$ Sensitive (S), moderately resistant (MR), or highly resistant (HR) to carbendazim (MBC).

y Inhibition rate was calculated on the basis of colony diameter in fungicidefree medium.

${ }^{\mathrm{z}}$ Change in inhibition rate: Rates in the 10th transfer divided by that of the first isolates.

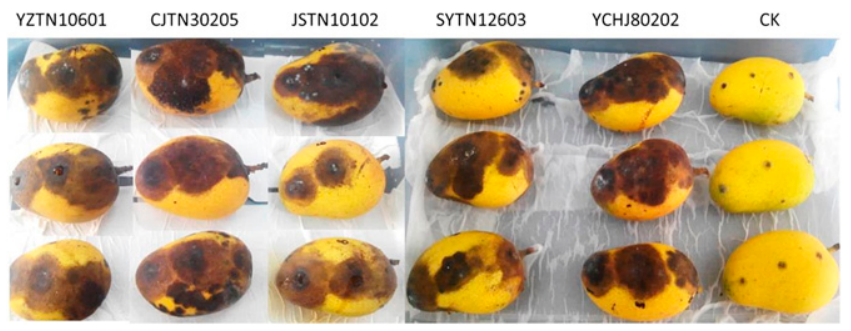

Fig. 1. Pathogenicity of Botryodiplodia theobromae at 5 days after inoculation. separation using Tukey's test $(P=0.05)$ was applied for comparison using SPSS Statistics 24.0. Graphs were constructed with Microsoft Excel (version 2010; Microsoft Corporation, Redmond, WA, U.S.A.).

\section{Results}

Resistance stability. The isolates with the three phenotypes (MBC-S, MBC-MR, and MBC-HR) were subjected to 10 successive transfers on fungicide-free PDA plates. For all MBC-S isolates (at the 1st and 10th transfer), the inhibition rates were more than $93 \%$ when cultured on PDA containing MBC at $5 \mu \mathrm{g} / \mathrm{ml}$, indicating that these isolates were sensitive to MBC (Table 1). For the MBC-MR and MBC-HR isolates, the inhibition rates of the isolates from the 10th transfer on PDA containing MBC at $500 \mu \mathrm{g} / \mathrm{ml}$ ranged from 14.6 to 34.2 and -5.0 to $6.5 \%$, respectively. After 10 successive transfers on a fungicide-free medium, the change in the inhibition rate for most isolates was close to onefold (Table 1). Two isolates (YZJH10201 and SYTN12603) were exceptions, and their change in inhibition rate was approximately twofold. However, all subcultured populations of isolates tested retained their original phenotypes during the 10 subcultures. Therefore, sensitivity to MBC was relatively stable regardless of phenotype.

Pathogenicity. The wounded site developed small, water-soaked spots on mango 2 days after inoculation with the $B$. theobromae isolates. At 5 days, black, water-soaked lesions had quickly developed on all mango fruit inoculated with $B$. theobromae, and flesh rot was also observed at these sites but not for the control (Fig. 1). All isolates were pathogenic to mango and highly virulent. There was no evidence of infection in any of the control fruit. The virulence of MBC-R (MBC-MR and MBC-HR) isolates compared with that of MBC-S isolates did not decrease.

Mycelial growth and temperature sensitivity. Compared with that of MBC-S isolates, the mycelial growth of MBC-R isolates did not change significantly on PDA medium at $30^{\circ} \mathrm{C}$ for $36 \mathrm{~h}$ (Table 2). The isolates with the three phenotypes were tested for their ability to grow at various temperatures on PDA and were severely inhibited when cultured at 10,15 , and $40^{\circ} \mathrm{C}$. The optimal temperature for both resistant and sensitive isolates was $30^{\circ} \mathrm{C}$. Compared with the sensitive isolates, the resistant isolates (MBC-MR and MBC-HR) had different temperature sensitivities at low and high temperatures (Table 2). The growth rate of the resistant isolates was significantly slower than that of the sensitive isolates at 15 and $20^{\circ} \mathrm{C}(P=0.05)$. However, the MBC-S isolates had slower growth than the resistant isolates at $40^{\circ} \mathrm{C}$. These results showed that the MBC-R isolates had low-temperature sensitivity on PDA.

Osmotic stress sensitivity. The test of glucose sensitivity showed that all isolates grew well on PDA with glucose. For glucose at less than $80 \mathrm{mg} / \mathrm{ml}$, the mycelial growth of all isolates increased with glucose concentration. At glucose concentrations greater than $80 \mathrm{mg} / \mathrm{ml}$, the mycelial growth of most isolates slightly decreased with increasing glucose concentrations (Fig. 2A). There were no significant differences between MBC-S isolates and MBC-R isolates when grown in the presence of a high glucose concentration $(150 \mathrm{mg} / \mathrm{ml})$ $(P=0.05)$.

For $\mathrm{NaCl}$ at less than $10 \mathrm{mg} / \mathrm{ml}$, the mycelial growth of all isolates increased with increasing $\mathrm{NaCl}$ concentration. When the $\mathrm{NaCl}$ concentration was greater than $20 \mathrm{mg} / \mathrm{ml}$, the mycelial growth of all isolates was increasingly inhibited with increasing $\mathrm{NaCl}$ concentration (Fig. 2B). When comparing among the isolates with the three

Table 2. Mycelia growth of Botryodiplodia theobromae isolates at different temperature for $36 \mathrm{~h}$

\begin{tabular}{|c|c|c|c|c|c|c|}
\hline \multirow[b]{2}{*}{ Phenotype $^{\mathrm{z}}$} & \multicolumn{6}{|c|}{ Growth $(\mathrm{mm})$ at each temperature ${ }^{y}$} \\
\hline & $15\left({ }^{\circ} \mathrm{C}\right)$ & $20\left({ }^{\circ} \mathrm{C}\right)$ & $25\left({ }^{\circ} \mathrm{C}\right)$ & $30\left({ }^{\circ} \mathrm{C}\right)$ & $35\left({ }^{\circ} \mathrm{C}\right)$ & $40\left({ }^{\circ} \mathrm{C}\right)$ \\
\hline MBC-S & $4.7 \pm 0.6 b$ & $31.3 \pm 1.52 b$ & $62.5 \pm 0.7 \mathrm{a}$ & $81.8 \pm 1.0 \mathrm{a}$ & $75.1 \pm 2.4 \mathrm{a}$ & $3.3 \pm 0.3 \mathrm{a}$ \\
\hline MBC-MR & $2.9 \pm 0.5 \mathrm{a}$ & $28.0 \pm 0.3 \mathrm{a}$ & $65.3 \pm 2.2 \mathrm{a}$ & $79.8 \pm 0.8 \mathrm{a}$ & $71.8 \pm 2.0 \mathrm{a}$ & $5.8 \pm 0.5 \mathrm{~b}$ \\
\hline MBC-HR & $3.4 \pm 0.2 \mathrm{a}$ & $27.5 \pm 0.6 \mathrm{a}$ & $62.6 \pm 3.9 \mathrm{a}$ & $78.1 \pm 0.9 \mathrm{a}$ & $75.2 \pm 3.6 \mathrm{a}$ & $4.9 \pm 0.4 \mathrm{~b}$ \\
\hline
\end{tabular}

\footnotetext{
y Values are means ( \pm standard deviation) of three experiments. Lowercase letters represent significant level $(P=0.05)$ according to the Tukey's test.
}

${ }^{\mathrm{z}}$ Sensitive (S), moderately resistant (MR), or highly resistant (HR) to carbendazim (MBC). 
phenotypes during growth in the presence of $\mathrm{NaCl}$ at $80 \mathrm{mg} / \mathrm{ml}$, the MBC-S isolates were more sensitive to high $\mathrm{NaCl}$ than the MBC-R isolates $(P=0.05)$.

Glycerol content. The glycerol content of MBC-S, MBC-MR, and MBC-HR isolates was $15.8,21.2$, and $17.5 \mathrm{mg} / \mathrm{g}$, respectively (Table 3). There were no significant differences between the resistant and sensitive isolates $(P=0.05)$.

Enzyme activity. The enzyme activities in the sensitive and resistant isolates are summarized in Table 3. The results showed that the enzyme activities varied among the three phenotypes. Compared with MBC-S isolates, the CAT activities of MBC-MR and MBCHR isolates were 2.3- and 3.7-fold, respectively. There were significant differences among the three resistance phenotypes $(P=0.05)$. Compared with the MBC-S isolates, the MBC-HR isolates had 1.3-fold higher GST activity. The MBC-R isolates had significantly higher CAT and GST activities than the MBC-S isolates $(P=0.05)$. For POD activity, no significant differences were found among the three groups of isolates. These results indicated that CAT and GST activity might have a certain role in conferring resistance to $\mathrm{MBC}$ in the highly resistant isolates of $B$. theobromae.

Cell membrane permeability. Cell membrane permeability was represented by the relative conductivity of distilled water containing mycelia. The relative conductivity of all isolates was increased
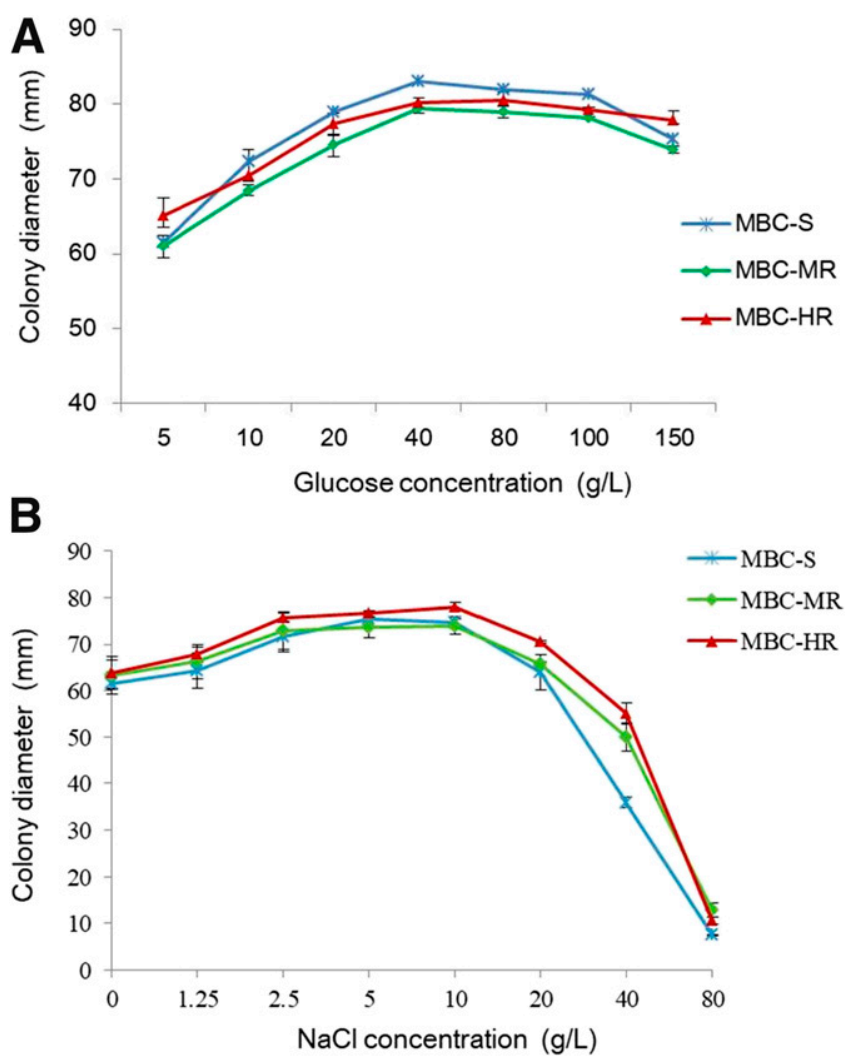

Fig. 2. Sensitivity of carbendazim (MBC)-resistant isolates and sensitive isolates of Botryodiplodia theobromae to glucose $(\mathbf{A})$ and $\mathrm{NaCl}(\mathbf{B})$ on potato dextrose agar. $\mathrm{S}=$ sensitive, $\mathrm{MR}=$ moderately resistant, and $\mathrm{HR}=$ highly resistant. Bars denote the standard error of three experiments. between 5 and $40 \mathrm{~min}$. The relative conductivity showed little increase after 80 min of treatment (Fig. 3).

The relative conductivity significantly increased with increasing MBC concentration. The results suggested that MBC might lead to increased cell membrane damage and mycelial electrolyte leakage of $B$. theobromae. A dose-response relationship showed that increasing the MBC concentration resulted in a progressive increase in the relative conductivity of all isolates. There was a significant difference in the average relative conductivity among the isolates with the three phenotypes, and the relative conductivity of MBC-S isolates increased significantly when they were treated with increasing concentrations of MBC. However, the relative conductivity of the MBC-MR
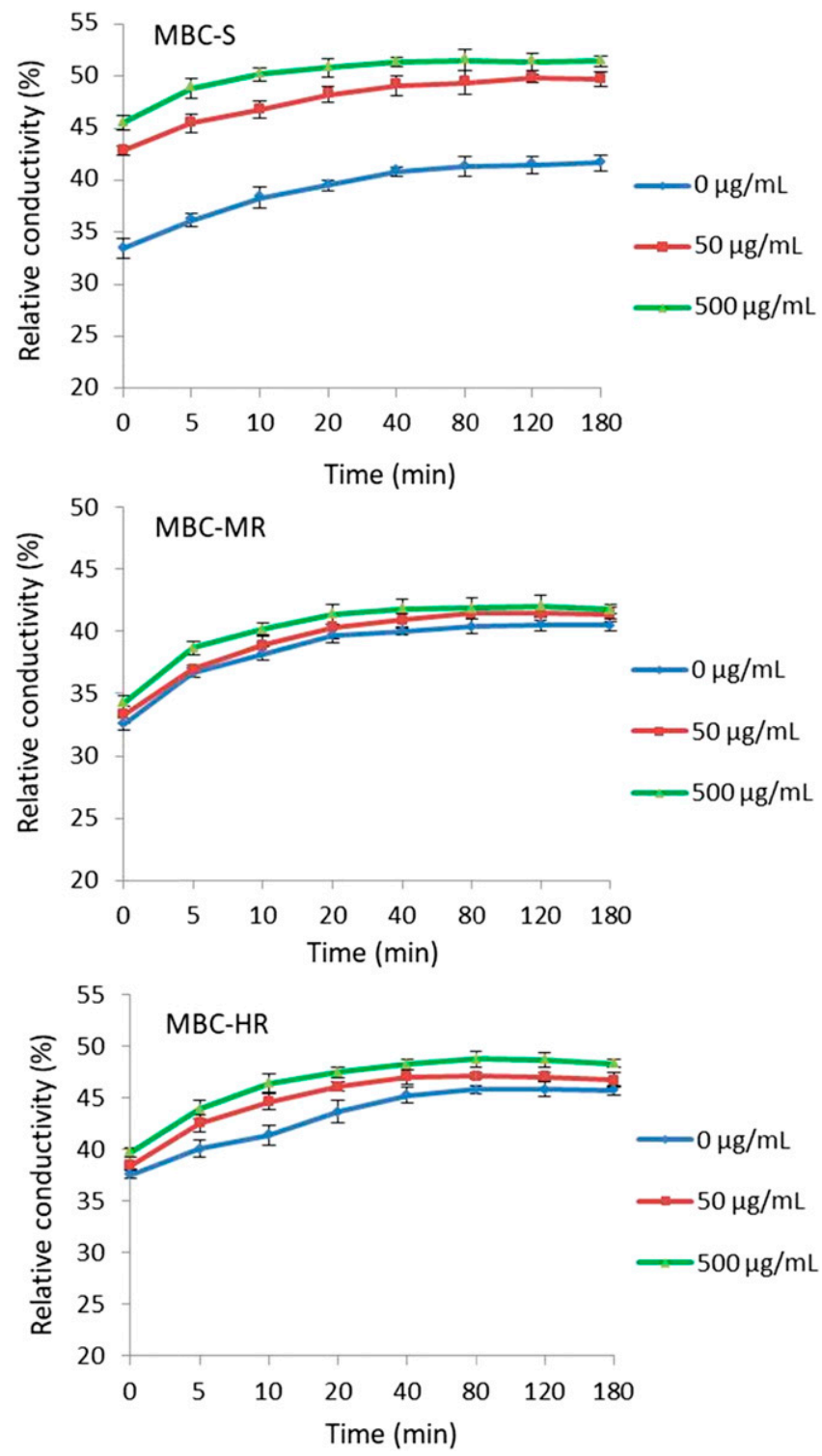

Fig. 3. Relative conductivity of the mycelia of Botryodiplodia theobromae isolates under carbendazim $(\mathrm{MBC})$ treatment. $S=$ sensitive, $M R=$ moderately resistant, and $\mathrm{HR}=$ highly resistant. Bars denote the standard error of three experiments.

Table 3. Glycerol, protein content, and enzyme activities in the mycelia of Botryodiplodia theobromae isolates ${ }^{\mathrm{y}}$

\begin{tabular}{lccccc}
\hline Phenotype $^{\mathbf{z}}$ & Glycerol $(\mathbf{m g} / \mathbf{g})$ & Protein $(\mathrm{g} /$ liter) & CAT $(\mathbf{U} / \mathbf{m g}$ of total protein) & POD (U/mg of total protein) & GST (U/mg of total protein) \\
\hline MBC-S & $15.8 \pm 4.2 \mathrm{a}$ & $380.0 \pm 21.2 \mathrm{a}$ & $10.9 \pm 2.4 \mathrm{a}$ & $43.4 \pm 4.4 \mathrm{a}$ & $160.0 \pm 13.2 \mathrm{a}$ \\
MBC-MR & $21.2 \pm 3.1 \mathrm{a}$ & $450.0 \pm 24.6 \mathrm{a}$ & $24.9 \pm 4.6 \mathrm{~b}$ & $42.9 \pm 3.3 \mathrm{a}$ & $180.4 \pm 21.7 \mathrm{ab}$ \\
MBC-HR & $17.5 \pm 2.9 \mathrm{a}$ & $400.3 \pm 28.2 \mathrm{a}$ & $40.6 \pm 4.1 \mathrm{c}$ & $51.1 \pm 4.0 \mathrm{a}$ & $208.5 \pm 18.7 \mathrm{~b}$ \\
\hline
\end{tabular}

${ }^{\text {y }} \mathrm{CAT}=$ catalase, $\mathrm{POD}=$ peroxidase , and GST $=$ glutathione S-transferase. Values are means ( \pm standard deviation) of three experiments. Lowercase letters represent significant level $(P=0.05)$ according to the Tukey's test.

${ }^{\mathrm{z}}$ Sensitive (S), moderately resistant (MR), or highly resistant (HR) to carbendazim (MBC). 
and MBC-HR isolates increased slightly when compared with that of the MBC-S isolates (Fig. 3). Statistical analysis showed that the relative conductivities of the $\mathrm{MBC}-\mathrm{MR}$ and $\mathrm{MBC}-\mathrm{HR}$ isolates were significantly lower than those of the MBC-S isolates with MBC treatment $(P=0.05)$.

Comparison of the DNA sequences of the $\beta$-tubulin gene from MBC-R and MBC-S isolates. Analysis of the 850- to 900-bp fragment of the $\beta$-tubulin gene nucleotide sequences from the 12 isolates showed $99 \%$ similarities to the sequence of $L$. theobromae (B. theobromae, GenBank accession number KX120057.1). When comparing with the $\beta$-tubulin genes from other fungi, the $\beta$-tubulin gene from $B$. theobromae JSJH10101 isolates was predicted to encode 258 amino acids, and the deduced amino acid sequence of the $\beta$ tubulin gene from $B$. theobromae showed $95 \%$ identity to that of Aspergillus flavus (GenBank accession number M38265.1).

Analysis of the DNA sequence of the $\beta$-tubulin gene revealed that all of the MBC-R isolates' DNA sequences differed from those of the MBC-S isolates (Fig. 4). After the DNA sequences were translated into amino acid sequences, three MBC-S isolates were found to be identical and exhibited 100\% homology. Comparison of the amino acid sequences of the $\beta$-tubulin genes from the MBC-R and MBC-S isolates revealed amino acid replacements in the MBC-R isolates (Fig. 4). Five MBC-HR isolates carried a point mutation at codon 198 (E198A); the replacement was a glutamic acid (GAG) to an alanine (GCG) in the $\beta$-tubulin gene. Four MBC-MR isolates carried a point mutation at codon position 200 (F200Y); the replacement was a phenylalanine (TTC) to a tyrosine (TAC) in the $\beta$-tubulin gene.

\section{Discussion}

$\mathrm{MBC}$ is an important benzimidazole fungicide. Fungicide resistance has been frequently reported in the last 10 years, and benzimidazole-resistant isolates of $B$. theobromae have become widespread in Hainan Province (Hu et al. 2009; Zhao et al. 2017). However, the resistance mechanisms of $B$. theobromae to MBC have not been reported. This study explored the possible resistance mechanisms to MBC based on analysis of the biochemical and molecular characteristics of field isolates of $B$. theobromae.

Stability, temperature sensitivity, fitness, and other characteristics of resistant isolates. An important factor in resistance management is the stability of resistance in the absence of selection pressure. The resistant isolates grew normally on PDA containing MBC at $500 \mu \mathrm{g} / \mathrm{ml}$ and maintained high-level resistance to $\mathrm{MBC}$ after 10 transfers on fungicide-free medium. This result indicated that the resistance of $B$. theobromae to MBC was stably inherited. Furthermore, the fitness of resistant isolates is an extremely important parameter regarding the risk for the development of resistance. Many studies have shown that MBC-R field isolates of fungal species might have sufficient parasitic fitness to compete with sensitive field isolates in the field (Liu et al. 2016; Malandrakis et al. 2012; Moyano et al. 2004; Sun et al. 2010). Some studies have also shown that the phenotypic characteristics of benzimidazole-resistant isolates include sensitivity to temperature. Mutations in the $\beta$-tubulin gene may have pleiotropic effects on fungal growth at high or low temperatures (Davidse 1986). Isolates with resistance to benzimidazole fungicides were sensitive under low or high temperature conditions, which may interfere with the fitness of resistant isolates (Ma et al. 2003, 2005). Laboratory mutants showed extremely high MBC resistance and reduced thermotolerance (Song et al. 2012; Zhang et al. 2010; Zou et al. 2006). However, there are differing findings such as highlevel MBC-resistant isolates of Cercospora beticola that showed no temperature sensitivity (Trkulja et al. 2013). Both MBC-R and MBC-S field strains of Fusarium graminearum shared similar temperature sensitivity (Chen et al. 2007). In this study, it was observed that the MBC-R isolates of $B$. theobromae were sensitive to low temperature, whereas they presented an enhanced tolerance to high temperature $\left(40^{\circ} \mathrm{C}\right)$. Moreover, there were no significant differences in sensitivity to high glucose concentrations between the resistant and sensitive isolates of $B$. theobromae. There have been reports that high osmotic sensitivity is not directly linked with resistance to dicarboximides and phenylpyrroles (Wang et al. 2014). However, fluazinamresistant mutants had a weaker capacity to regulate osmotic pressure (high glucose) than their fluazinam-sensitive parental strains (Fujimura et al. 2000; Shao et al. 2015). Compared with MBC-S isolates, MBC$\mathrm{R}$ isolates did not show significant changes in mycelial growth and pathogenicity, and MBC-R isolates were more tolerant than MBC$\mathrm{S}$ isolates to high temperature and high $\mathrm{NaCl}$ concentrations in our study. These results suggested that the MBC-R field isolates of $B$. theobromae had high parasitic fitness in the field.

The main biochemical characteristics of resistant isolates. Relative electrical conductivity is used to quantify cell membrane permeability. Recent studies have shown that fungicides can change the membrane permeability of phytopathogenic fungi. The cell membrane permeability of Sclerotinia sclerotiorum isolates treated with benzothiostrobin and dimethachlone was higher than that

198200

HLTN83108 (S)

YZTN10601(S)

HLTN10402 (HR)

YCHJ80202 (HR)

SYTN12603 (HR)

HLJH21617 (HR)

HLTN22602 (HR)

CJTN30204 (MR)

CJTN30205 (MR)

JSTN10102 (MR)

YZJH10201 (MR)
JSJH10101 (S)

GAGCCTTACAACGCCACCCTGTCCGTCCACCAGCTCGTTGAGAACTCGGACGAGACCTTCTGTATCGACAACGAGGCTCTGTACGACATC

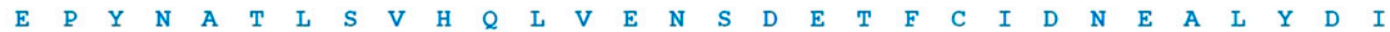
GAGCCTTACAACGCCACCCTGTCCGTCCACCAGCTCGTTGAGAACTCGGACGAGACCTTCTGTATCGACAACGAGGCTCTGTACGACATC

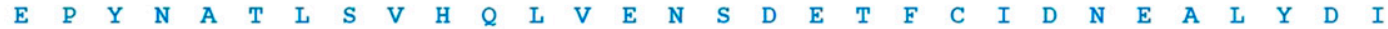
GAGCCTTACAACGCCACTCTGTCCGTCCACCAGCTTGTTGAGAACTCGGACGAGACCTTCTGTATCGACAACGAGGCTCTGTACGACATC

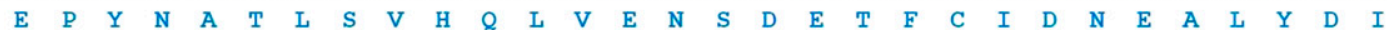
GAGCCTTACAACGCCACTCTGTCCGTCCACCAGCTCGTTGAGAACTCGGACGCGACCTTCTGTATCGACAACGAGGCTCTGTACGACATC

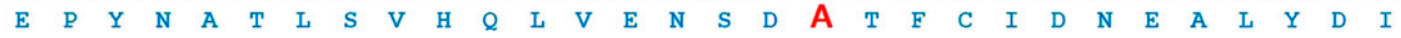
GAGCCTTACAACGCCACTCTGTCCGTCCACCAGCTCGTTGAGAACTCGGACGCGACCTTCTGTATCGACAACGAGGCTCTGTACGACATC

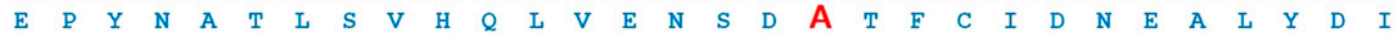
GAGCCTTACAACGCCACTCTGTCCGTCCACCAGCTCGTTGAGAACTCGGACGCGACCTTCTGTATCGACAACGAGGCTCTGTACGACATC

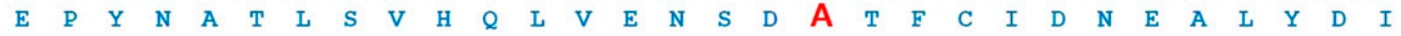
GAGCCTTACAACGCCACTCTGTCCGTCCACCAGCTCGTTGAGAACTCGGACGCGACCTTCTGTATCGACAACGAGGCTCTGTACGACATC

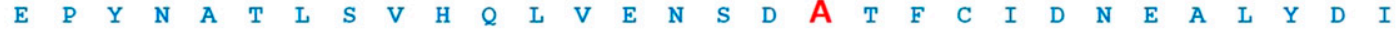
GAGCCTTACAACGCCACTCTGTCCGTCCACCAGCTCGTTGAGAACTCGGACGCGACCTTCTGTATCGACAACGAGGCTCTGTACGACATC

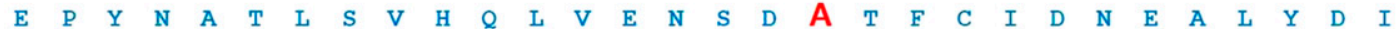
GAGCCTTACAACGCCACTCTGTCCGTCCACCAGCTCGTTGAGAACTCGGACGAGACCTACTGTATCGACAACGAGGCTCTGTACGACATC

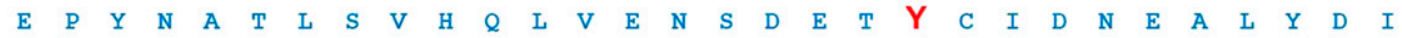
GAGCCTTACAACGCCACTCTGTCCGTCCACCAGCTCGTTGAGAACTCGGACGAGACCTACTGTATCGACAACGAGGCTCTGTACGACATC

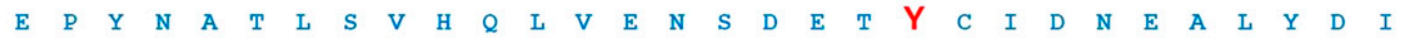
GAGCCTTACAACGCCACTCTGTCCGTCCACCAGCTCGTTGAGAACTCGGACGAGACCTACTGTATCGACAACGAGGCTCTGTACGACATC

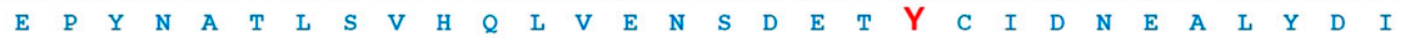
GAGCCTTACAACGCCACTCTGTCCGTCCACCAGCTCGTTGAGAACTCGGACGAGACCTACTGTATCGACAACGAGGCTCTGTACGACATC

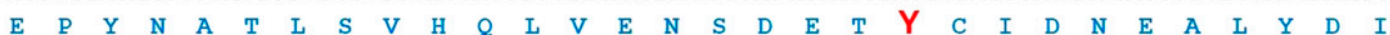

630

210

Fig. 4. Alignment of partial amino acid sequences of $\beta$-tubulin gene from carbendazim (MBC)-resistant isolates and -sensitive isolates of Botryodiplodia theobromae. A point mutation in MBC-HR and MBC-MR isolate were uncovered in the $\beta$-tubulin gene. $\mathrm{S}=$ sensitive, $\mathrm{MR}=$ moderately resistant, and $\mathrm{HR}=$ highly resistant. 
of untreated controls. Fungicides could lead to cell membrane damage and mycelium electrolyte leakage increase in S. sclerotiorum $(\mathrm{Li}$ et al. 2017; Xu et al. 2014). In this study, the relative conductivities of MBC-R isolates were significantly lower than those of MBC-S isolates when treated with $\mathrm{MBC}$. The increase in the relative conductivity of $B$. theobromae isolates increased cell membrane permeability. However, without MBC treatment, the relative conductivities of MBC-R isolates were slightly higher than those of MBC-S isolates.

In addition, some studies have shown that glycerol accumulation in cells might increase cell membrane permeability. The glycerol content of fluazinam-resistant mutants was significantly reduced compared with that of their corresponding parental strains (Fujimura et al. 2000). In contrast, dicarboximide-resistant mutants had significantly higher glycerol content than the wild-type strains (Duan et al. 2014). In this study, the glycerol contents were not different between resistant isolates and sensitive isolates.

It has been reported that some enzyme activities are related to fungicide resistance. In fungi, for example, POD and CAT activities have been reviewed as defense enzymes. GST is a multifunctional enzyme involved in the cellular detoxification of various pesticides, and metabolic detoxification capacity changes with enzyme activity. The resistant isolates had higher enzyme activities than the sensitive isolates, which might be related to the resistance to fungicides. It was observed that POD activities increased in fludioxonilresistant mutants compared with those in their parental strains (Duan et al. 2014). To determine the potential role of enzymes in resistance to $\mathrm{MBC}$ in $B$. theobromae, three enzymes (POD, CAT, and GST) were analyzed. In our studies, no significant differences in POD activities were found among the isolates with the three phenotypes. The CAT and GST activities of MBC-R isolates of $B$. theobromae were higher than those of MBC-S isolates, which might be related to resistance to MBC. As Sevastos et al. (2017) pointed out, GSTs may play a role in the detoxification of $\mathrm{MBC}$, which is at least partly responsible for the observed $\mathrm{MBC}$ resistance of an isolate of $F$. graminearum.

Sequence variation in the $\boldsymbol{\beta}$-tubulin gene. Many studies have confirmed that benzimidazole-resistant isolates collected from the field have codon changes at positions 198 and 200 in the $\beta$-tubulin gene (Cabanas et al. 2009; Sholberg et al. 2005; Yarden and Katan 1993). Target gene mutations have been associated with practical benzimidazole resistance problems in many plant pathogens, and these mutant pathogens have the characteristics of stability, temperature sensitivity, and no fitness penalties. In this article, we cloned and compared the $\beta$-tubulin genes of $B$. theobromae field isolates. Our studies confirmed amino acid substitutions (E198A and F200Y) that are known mechanisms of resistance to MBC fungicides. The results are as follows: the wild-type isolates (MBC-S) were fully sensitive, the F200Y isolates were moderately resistant, and the E198A isolates were highly resistant. This finding is in agreement with previous reports on Botrytis cinerea, Cladosporium fulvum, and Penicillium expansum (Leroux et al. 2002; Malandrakis et al. 2013; Yan et al. 2008), in which the resistant isolates with a mutation at position 198 exhibited a high level of resistance to benzimidazole fungicides. However, no mutation was detected in isolates of $P$. expansum moderately resistant to benzimidazole (Malandrakis et al. 2013). The $\beta$-tubulin gene of thiabendazoleresistant isolates of Gibberella pulicaris was not linked to thiabendazole resistance (Kawchuk et al. 2002). Additionally, there are other molecular mechanisms of resistance such as gene overexpression or gene deletion mutations that could be responsible for fungicide resistance. Deletion of the $\beta 1$-tubulin gene in the HR isolate GJ33 of G. zeae resulted in an increased resistance to MBC (Liu et al. 2010).

Concluding remarks and future research. The main purpose of this research was to evaluate the mechanism of MBC resistance in various field isolates of $B$. theobromae obtained from mango. The present study identified that all isolates resistant to MBC possessed a mutation in the $\beta$-tubulin gene. Therefore, benzimidazole fungicides fail to control stem-end rot infections caused by resistant isolates on mango in Hainan. The MBC-R field isolates of $B$. theobromae displayed resistance stability and high parasitic fitness in the field. It follows that fungicide application strategies should be changed. For example, the application of MBC must be avoided for the control of mango diseases in Hainan, and use of alternative fungicides with different modes of action could be adopted to delay or avoid the development of resistance. Any attempt to explain the correlation between benzimidazole resistance and the biochemical characterization would be speculative. MBC could lead to cell membrane damage and increase mycelium electrolyte leakage of $B$. theobromae. The cell membrane integrity of the resistant isolates was higher than that of the sensitive isolates when exposed to MBC, which may be related to the mechanism of MBC resistance. Furthermore, elevated CAT and GST activities may also be related to benzimidazole resistance. Additional molecular and biochemical studies will be conducted to elucidate the mechanism of $\mathrm{MBC}$ resistance in B. theobromae. A future goal is to develop a molecular method for the rapid detection of resistant genotypes.

\section{Literature Cited}

Albertini, C., Gredt, M., and Leroux, P. 1999. Mutations of the $\beta$-tubulin gene associated with different phenotypes of benzimidazole resistance in the cereal eyespot fungi Tapesia yallundae, and Tapesia acuformis. Pestic. Biochem. Physiol. 64:17-31.

Cabanas, R., Castella, G., Abarca, M., Bragulat, M., and Cabanes, F. 2009. Thiabendazole resistance and mutations in the beta-tubulin gene of Penicillium expansum strains isolated from apples and pears with blue mold decay. Pestic. Biochem. Physiol. 297:189-195.

Cai, M., Lin, D., Chen, L., Bi, Y., and Xiao, L. 2015. M233I Mutation in the $\beta$-tubulin of Botrytis cinerea confers resistance to zoxamide. Sci. Rep. 5: Article 16881.

Chen, C. J., Wang, J. X., Luo, Q. Q., Yuan, S. K., and Zhou, M. G. 2007. Characterization and fitness of carbendazim-resistant strains of Fusarium graminearum wheat scab. Pest Manage. Sci. 63:1201-1207.

Davidse, L. C. 1986. Benzimidazole fungicides: Mechanism of action and biological impact. Annu. Rev. Phytopathol. 24:43-65.

Deising, H. B., Reimann, S., and Pascholati, S. F. 2008. Mechanisms and significance of fungicide resistance. Brazil. J. Microbiol. 39:286-295.

Duan, Y.-B., Ge, C.-Y., and Zhou, M.-G. 2014. Molecular and biochemical characterization of Sclerotinia sclerotiorum laboratory mutants resistant to dicarboximide and phenylpyrrole fungicides. J. Pest Sci. 87:221-230.

Fujimura, M., Ochiai, N., Ichiishi, A., Usami, R., Horikoshi, K., and Yamaguchi, I. 2000. Fungicide resistance and osmotic stress sensitivity in os mutants of Neurospora crassa. Pestic. Biochem. Physiol. 67:125-133.

Hu, M. J., Shi, C., and An, Y. 2009. Resistance of Botryodiplodia theobromae to carbendazim and the fungicides screening using stem end rot of mango fruit as a control. Chin. J. Fruit Sci. 26:671-677.

Karunanayake, K. O. L. C., Sinniah, G. D., Adikaram, N. K. B., and Abayasekara, C. L. 2014. Cultivar differences in antifungal activity and the resistance to postharvest anthracnose and stem-end rot in mango (Mangifera indica L.). Australas. Plant Pathol. 43:151-159.

Kawchuk, L. M., Hutchison, L. J., Verhaeghe, C. A., Lynch, D. R., Bains, P. S., and Holley, J. D. 2002. Isolation of the $\beta$-tubulin gene and characterization of thiabendazole resistance in Gibberella pulicaris. Can. J. Plant Pathol. 24: 233-238.

Leroux, P., Fritz, R., Debieu, D., Albertini, C., Lanen, C., Bach, J., Gerdt, M., and Chapeland, F. 2002. Mechanisms of resistance to fungicides in field strains of Botrytis cinerea. Pest Manag. Sci. 58:876-888.

Li, J. L., Kang, T. H., Talab, K. M. A., Zhu, F. X., and Li, J. H. 2017. Molecular and biochemical characterization of dimethachlone resistant isolates of Sclerotinia sclerotiorum. Pestic. Biochem. Physiol. 138:15-21.

Liu, S. M., Che, Z. P., and Chen, G. Q. 2016. Multiple-fungicide resistance to carbendazim, diethofencarb, procymidone, and pyrimethanil in field isolates of Botrytis cinerea from tomato in Henan Province, China. Crop Prot. 84:56-61.

Liu, X., Yin, Y., Wu, J., Jiang, J., and Ma, Z. 2010. Identification and characterization of carbendazim-resistant isolates of Gibberella zeae. Plant Dis. 94:1137-1142.

Ma, Z., Oshimura, M. A., and Michailides, T. J. 2003. Identification and characterization of benzimidazole resistance in Monilinia fructicola from stone fruit orchards in California. Appl. Environ. Microbiol. 69:7145-7152.

Ma, Z., Yoshimura, M. A., Holtz, B. A., and Michailides, T. J. 2005 Characterization and PCR-based detection of benzimidazole resistant isolates of Monilinia laxa in California. Pest Manage. Sci. 61:449-457.

Malandrakis, A. A., Markoglou, A. N., Konstantinou, S., Doukas, E. G., Kalampokis, J. F., and Karaoglanidis, G. S. 2013. Molecular characterization, fitness and mycotoxin production of benzimidazole -resistant isolates of Penicillium expansum. Int. J. Food Microbiol. 162:237-244.

Malandrakis, A. A., Markoglou, A. N., and Ziogas, B. N. 2012. PCR-RFLP detection of the E198A mutation conferring resistance to benzimidazoles in field isolates of Monilinia laxa from Greece. Crop Prot. 39:11-17. 
Moyano, C., Gomez, V., and Melgarejo, P. 2004. Resistance to pyrimethanil and other fungicides in Botrytis cinerea populations collected on vegetable crops in Spain. J. Phytopathol. 152:484-490.

Sakalidis, M. L., Ray, J. D., Lanoiselet, V., Hardy, G. E. S., and Burgess, T. I. 2011. Pathogenic Botryosphaeriaceae associated with Mangifera indica in the Kimberley Region of Western Australia. Eur. J. Plant Pathol. 130:379-391.

Sevastos, A., Labroub, N. E., Flouri, F., and Malandrakis, A. 2017. Glutathione transferase-mediated benzimidazole-resistance in Fusarium graminearum. Pestic. Biochem. Physiol. 141:23-28.

Shao, W. Y., Zhang, Y., Ren, W. C., and Chen, C. G. 2015. Physiological and biochemical characteristics of laboratory induced mutants of Botrytis cinerea with resistance to fluazinam. Pestic. Biochem. Physiol. 117:19-23.

Sholberg, P. L., Harlton, C., Haag, P., Lévesque, C. A., O'Gorman, D., and Seifert, K. 2005. Benzimidazole and diphenylamine sensitivity and identity of Penicillium spp. that cause postharvest blue mold of apples using $\beta$-tubulin gene sequences. Postharvest Biol. Technol. 36:41-49.

Slippers, B., Johnson, G. I., Crous, P. W., Coutinho, T. A., Wingfield, B. D., and Wingfield, M. J. 2005. Phylogenetic and morphological re-evaluation of the Botryosphaeria species causing diseases of Mangifera indica. Mycologia 97:99-110.

Song, T. T., Ying, S. H., and Feng, M. G. 2012. High resistance of Isaria fumosorosea to carbendazim arises from the overexpression of an ATPbinding cassette transporter (ifT1) rather than tubulin mutation. J. Appl. Microbiol. 112:175-184.

Sun, H. Y., Wang, H. C., Chen, Y., Li, H. X., Chen, C. J., and Zhou, M. G. 2010. Multiple resistance of Botrytis cinerea from vegetable crops to carbendazim, diethofencarb, procymidone, and pyrimethanil in China. Plant Dis. 94:551-556.

Trkulja, N., Ivanović, Ž., Pfaf-Dolovac, E., Dolovac, N., Mitrović, M., Toševski, I., and Jović, J. 2013. Characterization of benzimidazole resistance of Cercospora beticola in Serbia using PCR-based detection of resistanceassociated mutations of the $\beta$-tubulin gene. Eur. J. Plant Pathol. 135:889-902.

Twumasi, P., Ohene-Mensa, G., and Moses, E. 2014. The rot fungus Botryodiplodia theobromae strains cross infect cocoa, mango, banana and yam with significant tissue damage and economic losses. Afr. J. Agric. Res. 9:613-619.
Wang, M., Chen, X. L., Yang, Y., Xue, R., Yang, N., and Zhou, H. Z. 2015. Resistance of mango stem-end rot to eight fungicides in Hainan Province. Chin. Agrochemicals 54:625-628.

Wang, Y., Hou, Y. P., Chen, C. J., and Zhou, M. G. 2014. Detection of resistance in Sclerotinia sclerotiorum to carbendazim and dimethachlon in Jiangsu Province of China. Australas. Plant Pathol. 43:307-312.

Xu, C. Y., Hou, Y. P., Wang, J. X., Yang, G. F., Liang, X. Y., and Zhou, M. G 2014. Activity of a novel strobilurin fungicide benzothiostrobin against Sclerotinia sclerotiorum. Pestic. Biochem. Physiol. 115:32-38.

Yan, L. Y., Chen, J., Zhang, C. Q., and Ma, Z. G. 2008. Molecular characterization of benzimidazole-resistant isolates of Cladosporium fulvum. FEMS Microbiol. Lett. 278:242-248.

Yang, Y., He, S. H., Zhang, S. J., and Hu, M. J. 2008. Resistance of mango anthracnose pathogen Colletotrichum gloesporioides to carbendazim in Hainan Province. Chin. J. Trop. Crops 29:73-77.

Yarden, O., and Katan, T. 1993. Mutations leading to substitutions at amino acids 198 and 200 of beta-tubulin that correlate with benomyl resistance phenotypes of field strains of Botrytis cinerea. Phytopathology 83:1478-1483.

Zhang, C. Q., Liu, Y. H., and Zhu, G. N. 2010. Detection and characterization of benzimidazole resistance of Botrytis cinerea in greenhouse vegetables. Eur. J. Plant Pathol. 126:509-515.

Zhang, Y. 2011. Mango industrial chain in Hainan. Chin. J. Trop. Agric. 32:75-80.

Zhao, L., Yang, Y., Wang, M., He, R., and Chen, M. C. 2017. Sensitivities of carbendazim-resistance and fitness of Botryodiplodia theobromae strains from mango in Hainan. Chin. J. Pestic. Sci. 19:1-9.

Zhou, M. G., and Wang, J. X. 2001. Study on sensitivity base-line of Fusarium graminearum to carbendazim and biological characters of MBC-resistant strains. Acta Phytopathol. Sin. 31:366-370.

Zhou, M. G., Ye, Z. Y., and Liu, J. F. 1994. Advance in fungicide resistance in China. J. Nanjing Agr. Univ. China 17:33-41.

Zou, G., Ying, S. H., Shen, Z. H., and Feng, M. G. 2006. Multisited mutations of beta-tubulin are involved in benzimidazole resistance and thermotolerance of fungal biocontrol agent Beauveria bassiana. Environ. Microbiol. 8: 2096-2105. 